\title{
COMPARISON OF STANDING LONG JUMP TECHNIQUE PERFORMED BY SUBJECTS FROM DIFFERENT AGE GROUPS
}

\author{
Marijana Hraski, Željko Hraski, Ivan Prskalo \\ University of Zagreb, Zagreb, Croatia
}

\begin{abstract}
Background. The aim of this study was to determine kinematic parameters relevant for the proficient performance of standing long jump (SLJ) test in boys and adolescents.

Methods. The investigation was conducted on 120 participants divided into five experimental groups of 20 boys and adolescents aged 4-18 and one control group composed of 20 students from the second year of Faculty of Kinesiology whose performance was considered as a model of proficient execution of analysed test. The set of variables was composed of 15 kinematic parameters. For determining the influence of selected kinematic parameters on proficiency of standing long jump test, the Stepwise Regression Analyses was used.

Results. The results showed the existence of specific relationship between selected kinematic parameters that significantly affected the execution of standing long jump test in each age group.

Conclusion. It can be concluded that, according to analysed kinematic parameters, technique of standing long jump significantly differ from early age to maturity.
\end{abstract}

Keywords: explosive strength, motor assessment tools, motor development, jumps, technique.

\section{INTRODUCTION}

$\mathrm{S}$ tanding long jump is a standard test for the assessment of lower limb explosive strength, which is one of the determinants of success in all activities that require a demonstration of the maximum muscle force in the shorter period of time (Newton \& Kreamer, 1994).

This test is very often used in education, sport and recreation for measuring children, students, athletes, and adults in order to assess the levels of individual motor abilities, as well as for a more objective evaluation of the teaching and training process (Pišot \& Planinšec, 2010; Popeska, Georgiev, \& Mitevski, 2009; Vitasalo, 1988).

The objective of the standing long jump is that the body of a subject is projected horizontally from one place to another, as far as possible from the take-off line. The subject starts from a static position and generates a large horizontal and vertical velocity passing through half squat position followed by coordinated arm swing and both feet take-off. The take-off is characterised by a large body inclination (take-off angle). In the flight phase comes the blocking action of the arms with legs moving forward preparing for landing on both feet. The respondent usually lands with emphasized forward bent and extended legs, with feet away in front of the hips. For successful jump, the respondent must keep a balance after landing avoiding falling backward (Seyfarth, Friedrich, Wank \& Blickhan, 1999; Wakai \& Linthorne, 2005).

The success in the standing long jump is determined by the total length of the jump $\left(d_{t}\right)$, which is the horizontal distance from the take-off line to the landing line measured by the nearest point of contact on the landing (back of the heels). It can be said that the overall performance of a jump depends on the sum of three components: the length at take-off $\left(d_{1}\right)$, flight distance $\left(d_{2}\right)$ and 


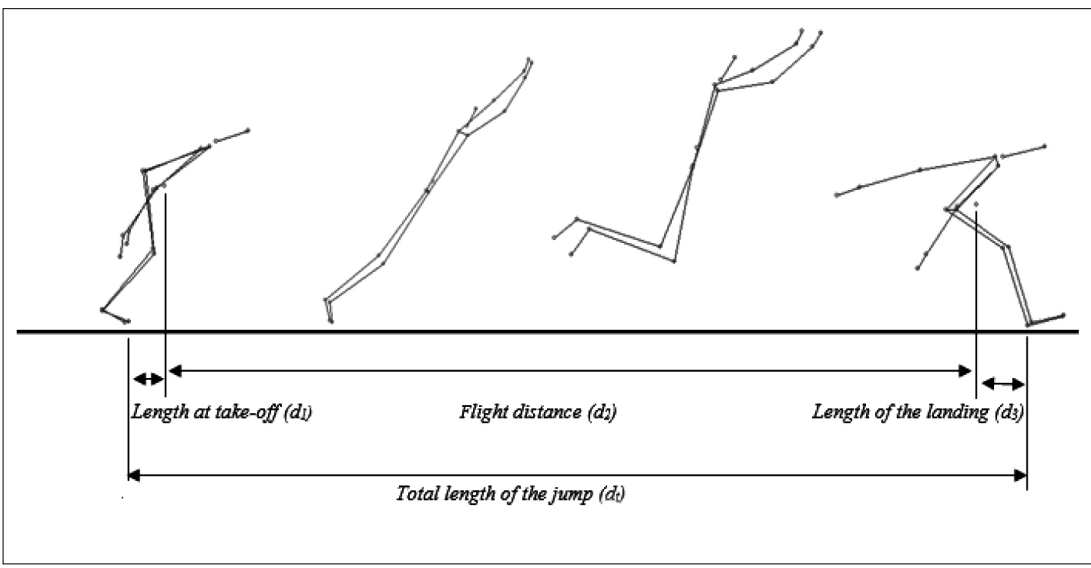

Figure. Standing long jump performed by students from the Faculty of Kinesiology

the length of the landing $\left(\mathrm{d}_{3}\right)$ (Wakai \& Linthorne, 2005) (Figure).

Only in case when all the aforementioned requirements and standards of the standing long jump performance are satisfied it can be said that the test measures the explosive strength of the lower extremities. However, given the fact that horizontal jump of the human body requires optimum coordination and muscle strength (Malina, 2004), numerous studies have concluded that standing long jump is a complex motor task (Blackburn \& Morrissey, 1998; Domire \& Challis, 2010; Fukashiro et al., 2005; Nagano, Komura \& Fukashiro, 2007; Wakai \& Linthorne, 2005).

Mackała, Stodolka, Siemienski, and Čoh (2012) investigated the effects of several variables on the preparatory and take-off phases of the standing long jump, including individual lower extremity joint angles, take-off angle, centre of mass trajectory and segmental peak velocities. Based on the obtained results they concluded that there was statistically significant difference between the standing long jump from different starting positions of knee angle and trunk bend. Szerdiova, Simsik, and Dolna (2012) analysed the impact of upper extremity angular momentum and alterations in kinematics (centre of mass trajectory, horizontal and vertical velocities at take-off, takeoff angle) on the length of standing long jumps with and without arm swing. Based on the results the authors concluded that there were statistically significant differences in jumps from different initial positions. Therefore, it can be assumed that motor coordination and technical performance have a great influence on the final outcome of the standing long jump, rather than the explosive strength of the individual (Lorger, M. Hraski, \& Ž. Hraski, 2012).
Following that, standing long jump can be considered as a complex movement that requires a high level of coordination skills in order to achieve maximum performance of the jump. The aim of this study was to determine kinematic parameters relevant for the proficient performance of standing long jump (SLJ) test in boys and adolescents. In accordance with the defined research aim, we hypothesized that there would be a significant influence of certain kinematic parameters on the proficiency of standing long jump test performance in boys and adolescents aged $4-18$ years.

\section{METHODS}

Participants. The investigation was conducted on 120 participants divided into five experimental groups of 20 boys and adolescents aged 4-18 from the city of Zagreb, and the control group composed of 20 students from the second year of the Faculty of Kinesiology, University of Zagreb, whose performance was considered as a model of proficient execution of analysed test (Table 1).

Table 1. Participants included in this study

\begin{tabular}{|c|c|c|c|c|c|c|}
\hline $\begin{array}{c}\text { Variable/ } \\
\text { Group }\end{array}$ & $\begin{array}{c}\mathbf{4 - 6} \\
\text { years }\end{array}$ & $\begin{array}{c}\mathbf{7 - 9} \\
\text { years }\end{array}$ & $\begin{array}{c}\mathbf{1 0}-\mathbf{1 2} \\
\text { years }\end{array}$ & $\begin{array}{c}\mathbf{1 3 - 1 5} \\
\text { years }\end{array}$ & $\begin{array}{c}\mathbf{1 6}-\mathbf{1 8} \\
\text { years }\end{array}$ & Students \\
\hline $\begin{array}{c}\text { Height } \\
(\mathrm{cm})\end{array}$ & 115.15 & 134.99 & 150.35 & 170.31 & 180.02 & 182.99 \\
\hline $\begin{array}{c}\text { Weight } \\
(\mathrm{kg})\end{array}$ & 21.25 & 34.15 & 42.98 & 64.06 & 73.02 & 82.43 \\
\hline
\end{tabular}

Variables. The set of variables was composed of 15 kinematic parameters that are important for defining the model, relevant for the proficient performance of the standing long jump (Ashby \& Delp, 2006; Ashbby \& Heegaard, 2002; Fukashiro et al., 2005; Horita, Kitamura \& Kohno, 1991; Wakai \& Linthorne, 2005; W. Wu, J. Wu, Lin, 
Table 2. Kinematic parameters determining the standing long jump

\begin{tabular}{|l|c|c|}
\hline \multicolumn{1}{|c|}{ Variable } & Mark & Unit \\
\hline Shoulder angle at the beginning of the preparatory phase & SABPP & $\circ$ \\
\hline Shoulder angle at the lowest point of the centre of gravity & SALCG & $\circ$ \\
Hip angle at the lowest point of the centre of gravity & HALCG & $\circ$ \\
Knee angle at the lowest point of the centre of gravity & KALCG & $\circ$ \\
\hline Elbow angle at take-off & EATO & $\circ$ \\
\hline Shoulder angle at take-off & SATO & $\circ$ \\
Hip angle at take-off & HATO & $\circ$ \\
Knee angle at take-off & KATO & $\circ$ \\
Take-off angle & TOA & $\circ$ \\
Elbow angle at the highest point of the centre of gravity & EAHCG & $\circ$ \\
Shoulder angle at the highest point of the centre of gravity & SAHCG & $\circ$ \\
Landing angle & LA & $\circ$ \\
Vertical velocity at take-off & VVTO & $\mathrm{cm} / \mathrm{s}$ \\
Horizontal velocity at take-off & HVTO & $\mathrm{cm} / \mathrm{s}$ \\
Jump length & JL & $\mathrm{cm}$ \\
\hline
\end{tabular}

\& Wang, 2003; Zhouyi, Yoshimasa, Yun, \& Kazuhiko, 2010) (Table 2). All variables are described and analysed through four basic phases of the jump (1. Preparatory phase, 2. Phase at take-off, 3. Flight phase, and 4. Landing phase), describing the geometry of the body, velocity of segments and the centre of gravity, as well as the temporal and spatial parameters of the jump.

Measurement protocol. The study was conducted in kindergartens, schools and colleges in the city of Zagreb. All subjects voluntarily participated in the study.

Collection of video data was made using two digital video cameras operating at the rate of 60 frames per second. All subjects were in the sports footwear and clothing. The test was performed on standing long jump track with marked start line and a measuring scale in centimetres. Respondents had three test trials followed by the three executions of the standing long jump test. The longest jump of each respondent was subjected to further analysis. The collected videos were processed by regular Ariel Performance Analysis System procedure.

Data processing. The influence of specific kinematic parameters on the proficiency of standing long jump performance was examined by Stepwise Multiple Regression Analysis, using Forward and Backward Stepwise models (method of gradual extension of the model and the method of gradual reduction of the model).

\section{RESULTS}

Based on the results, obtained by Stepwise Multiple Regression Analysis, it is evident that for a group of students of the Faculty of Kinesiology, whose performance was considered as a model of proficient execution of analysed test, a statistically significant influence of certain kinematic parameters on the proficiency of standing long jump (Tables 3 and 4) exists.

Results obtained by gradual extension of the model of kinematic parameters showed that the length of the jump was significantly affected by horizontal velocity at take-off, as well as by the variables that defined the arms swing - elbow angle at take-off, shoulder angle at the highest point of the centre of gravity during the flight and shoulder angle at the beginning of the preparatory phase.

Results of Stepwise Multiple Regression Analysis, obtained by a gradual reduction of the model of kinematic parameters, gave a more detailed description of a model of standing long jump performance.

Namely, on the base of obtained results (Table 4) it can be suggested that the tested standing long jump, together with the parameter of horizontal velocity at take-off and elbow angle at take-off, is also determined by the angle of take-off.

Tables 5 and 6 show the results of Stepwise Multiple Regression Analysis obtained by gradual extension of the model of kinematic parameters and the method of gradual reduction of the kinematic parameters for a group of boys aged 4 to 6 years. From the tagged $\mathrm{p}$-values that are significant at the level $p \leq .05$, it can be identified that there is also a statistically significant influence of certain kinematic parameters on the length of the standing long jump. However, unlike the students of the Faculty of Kinesiology, for a group of boys aged 


\begin{tabular}{|c|c|c|c|}
\hline \multirow{2}{*}{ Regression model } & \multicolumn{3}{|c|}{ F-value (10.9)=41.914 } \\
\hline Variable & $\begin{array}{c}\text { Standardised Beta } \\
\text { regression coproficient }\end{array}$ & $\boldsymbol{t}$-value & $p$-level \\
\hline HVTO & 1.55 & 2.33 & $* .05$ \\
\hline EATO & 0.41 & 3.77 & $* .00$ \\
\hline VVTO & -0.91 & -0.98 & .35 \\
\hline HALCG & 0.08 & 1.30 & .22 \\
\hline SAHCG & -0.30 & -3.90 & $* .00$ \\
\hline SABPP & 0.21 & 3.03 & $* .01$ \\
\hline LA & 0.21 & 1.99 & 0.8 \\
\hline SALCG & 0.20 & 2.32 & $* \mathbf{0 . 5}$ \\
\hline EAHCG & -0.16 & -1.58 & .15 \\
\hline TOA & 1.24 & 1.17 & .27 \\
\hline
\end{tabular}

Table 3. Forward Stepwise Multiple Regression Analysis - method of gradual extension of the model for a group of students of the Faculty of Kinesiology

Note. $* p \leq .05$.

\begin{tabular}{|c|c|c|c|}
\hline Regression model & \multicolumn{3}{|c|}{$F-$ value $(3.16)=34.087$} \\
\hline Variable & $\begin{array}{l}\text { Standardised Beta } \\
\text { regression coproficient }\end{array}$ & $t$-value & $p$-level \\
\hline EATO & 0.39 & 3.80 & $* .00$ \\
\hline TOA & 0.39 & 3.64 & $* .00$ \\
\hline HVTO & 0.80 & 6.79 & $* .00$ \\
\hline
\end{tabular}

Table 4. Backward Stepwise Multiple Regression Analysis - method of gradual reduction of the model for a group of students of the Faculty of Kinesiology

\begin{tabular}{|c|c|c|c|}
\hline \multirow{2}{*}{ Regression model } & \multicolumn{3}{|c|}{$F$-value (1.18)= 44.126 } \\
\hline Variable & $\begin{array}{c}\text { Standardised Beta } \\
\text { regression coproficient }\end{array}$ & $t$-value & $p$-level \\
\hline HVTO & 0.96 & 8.26 & $* .00$ \\
\hline LA & 0.22 & 1.97 & .07 \\
\hline VVTO & 0.25 & 2.24 & $* .04$ \\
\hline EATO & -0.20 & -1.84 & .09 \\
\hline
\end{tabular}

Note. $* p \leq .05$.

Table 5. Forward Stepwise Multiple Regression Analysis - method of gradual extension of the model for a group of boys aged 4 to 6 years

Note. $* p \leq .05$.

\begin{tabular}{|c|c|c|c|}
\hline Regression model & \multicolumn{3}{|c|}{$F$-value (4.15) $=20.597$} \\
\hline Variable & $\begin{array}{c}\text { Standardised Beta } \\
\text { regression coproficient }\end{array}$ & $t$-value & $p$-level \\
\hline HVTO & 0.84 & 6.64 & $* .00$ \\
\hline
\end{tabular}

Table 6. Backward Stepwise Multiple Regression Analysis - method of gradual reduction of the model for a group of boys aged 4 to 6 years

Note. $* p \leq .05$.

4-6 years the length of the jump depended on the horizontal velocity at take-off and the vertical velocity at take-off.

Results of Stepwise Multiple Regression Analysis, obtained by gradual extension of the model of kinematic parameters and the method of gradual reduction of the kinematic parameters for a group of boys aged 7 to 9 years are shown in Tables 7 and 8 . Referring to these results we can claim that in boys aged 7-9 years there is also a statistically significant influence of certain kinematic parameters on the proficiency of the standing long jump, i.e. the length of the jump depends on horizontal velocity at take-off and vertical velocity at take-off, as well as, opposed to the group 4- to 6 -year-olds, on hip angle at the lowest point of the centre of gravity during the preparatory phase, shoulder angle at take-off and take-off angle. 
Table 7. Forward Stepwise Multiple Regression Analysis - method of gradual extension of the model for a group of boys aged 7 to 9 years

Note. $* p \leq .05$.

\begin{tabular}{|c|c|c|c|}
\hline \multirow{2}{*}{ Regression model } & \multicolumn{3}{|c|}{$F$-value (3.16)= 44.771 } \\
\hline Variable & $\begin{array}{c}\text { Standardised Beta } \\
\text { regression coproficient }\end{array}$ & $t$-value & $p$-level \\
\hline HVTO & 0.80 & 9.61 & $* .00$ \\
\hline SATO & 0.19 & 1.52 & .15 \\
\hline VVTO & 0.23 & 3.01 & $* .01$ \\
\hline HALCG & -0.20 & -2.63 & $* .02$ \\
\hline SAHCG & 0.23 & 1.91 & .08 \\
\hline KALCG & 0.13 & 1.79 & .10 \\
\hline LA & 0.12 & 1.33 & .21 \\
\hline
\end{tabular}

Table 8. Backward Stepwise Multiple Regression Analysis- method of gradual reduction of the model for a group of boys aged 7 to 9 years

Note. $* p \leq .05$

\begin{tabular}{|c|c|c|c|}
\hline Regression model & \multicolumn{3}{|c|}{$F$-value (7.12)=30.797 } \\
\hline Variable & $\begin{array}{c}\text { Standardised Beta } \\
\text { regression coproficient }\end{array}$ & $t$-value & $p$-level \\
\hline SATO & 0.33 & 3.79 & $* .00$ \\
\hline TOA & 0.35 & 3.36 & $* .00$ \\
\hline HVTO & 0.95 & 8.69 & $* .00$ \\
\hline
\end{tabular}

As with the previous groups of subjects, a statistically significant influence of selected kinematic parameters on the proficiency of standing long jump performance is noticeable in the group of boys aged 10 to 12 years (Tables 9 and 10). Based on the results of the Stepwise Multiple Regression Analysis, it is evident that the length of the jump also depends on the vertical velocity at take-off, but opposite to the group of 4- to 6- and 7- to 9-year-olds. There are additional parameters that more precisely define the geometry of the body before take-off, at the very moment at takeoff and during the flight phase, knee angle at the lowest point of the centre of gravity during the preparatory phase, hip angle at take-off, takeoff angle and shoulder angle at the highest point of the centre of gravity during the flight phase. Furthermore, opposite to the group of subjects aged 4 to 6 and 7 to 9 years, in a boys aged 10 to 12 years, a statistically significant influence on the length of the jump has an angle of landing.
Table 9. Forward Stepwise Multiple Regression Analysis - method of gradual extension of the model for a group of boys aged 10 to 12 years

Note. ${ }^{*} p \leq .05$.

\begin{tabular}{|c|c|c|c|}
\hline \multirow{2}{*}{ Regression model } & \multicolumn{3}{|c|}{$F$-value (2.17) $=\mathbf{3 6 . 7 6 1}$} \\
\hline Variable & $\begin{array}{c}\text { Standardised Beta } \\
\text { regression coproficient }\end{array}$ & $\boldsymbol{t}$-value & $\boldsymbol{p}$-level \\
\hline HVTO & -0.23 & -0.27 & .80 \\
\hline VVTO & 2.76 & 1.70 & .13 \\
\hline LA & 0.30 & 2.57 & $* .03$ \\
\hline HATO & -0.36 & -2.56 & $* .03$ \\
\hline SAHCG & -0.21 & -2.25 & $* .05$ \\
\hline KALCG & -0.39 & -2.97 & $* .02$ \\
\hline HALCG & 0.33 & 2.24 & .06 \\
\hline TOA & -3.15 & -1.54 & .16 \\
\hline KATO & 0.35 & 2.26 & .05 \\
\hline SABPP & -0.15 & -1.35 & .22 \\
\hline SALCG & 0.13 & 1.16 & .28 \\
\hline
\end{tabular}




\begin{tabular}{|c|c|c|c|}
\hline Regression model & \multicolumn{3}{|c|}{$F$-value (11.8) $=\mathbf{1 4 . 8 4 5}$} \\
\hline Variable & $\begin{array}{c}\text { Standardised Beta } \\
\text { regression coproficient }\end{array}$ & $t$-value & $p$-level \\
\hline TOA & -2.13 & -8.50 & $* .00$ \\
\hline VVTO & 2.06 & 8.19 & $* .00$ \\
\hline
\end{tabular}

Table 10. Backward Stepwise Multiple Regression Analysis - method of gradual reduction of the model for a group of boys aged 10 to 12 years

Based on the results obtained by Stepwise Multiple Regression Analysis by the method of gradual extension of the models and methods of gradual reduction of kinematic parameters for a group of subjects aged 13 to 15 years, it is evident that there is also a statistically significant influence of certain variables on the performance of standing long jump (Table 11 and 12). As a difference to the results of a group of subjects from 4 to 6,7 to 9 and 10 to 12 years, in a group of 13- to 15 -year-olds, parameter vertical velocity at take-off is omitted, and variables of horizontal velocity at take-off and hip angle at take-off are dominant.
From the results shown in Tables 13 and 14 it can be seen that, as with the previously analysed groups of subjects, for adolescents (aged 16-18 years), the proficiency of the standing long jump is statistically significantly determined by such variables as the horizontal velocity at take-off, hip angle at take-off, take-off angle and vertical velocity of take-off.

Namely, once again it has been found that a variables of $C G$ velocity during the take-off and variables involved in defining the geometry of the body at the moment at take-off, are dominant.

\begin{tabular}{|c|c|c|c|}
\hline Regression model & \multicolumn{3}{|c|}{$F$-value (1.18)=36.291 } \\
\hline Variable & $\begin{array}{c}\text { Standardised Beta } \\
\text { regression coproficient }\end{array}$ & $t$-value & $p$-level \\
\hline HVTO & 1.96 & 2.93 & $* .01$ \\
\hline TOA & 2.30 & 1.75 & .10 \\
\hline EATO & 0.20 & 1.82 & .09 \\
\hline HATO & 0.26 & 2.25 & $* .04$ \\
\hline VVTO & -1.72 & -1.51 & .15 \\
\hline
\end{tabular}

Table 11. Forward Stepwise Multiple Regression Analysis - method of gradual extension of the model for a group of boys aged 13 to 15 years

\begin{tabular}{|c|c|c|c|}
\hline Regression model & \multicolumn{3}{|c|}{$F$-value (5.14) $=16.454$} \\
\hline Variable & $\begin{array}{c}\text { Standardised Beta } \\
\text { regression coproficient }\end{array}$ & $t$-value & $p$-level \\
\hline HVTO & 0.82 & 6.02 & $* .00$ \\
\hline
\end{tabular}

Table 12. Backward Stepwise Multiple Regression Analysis - method of gradual reduction of the model for a group of boys aged 13 to 15 years

Note. ${ }^{*} p \leq .05$.

\begin{tabular}{|c|c|c|c|}
\hline \multirow{2}{*}{ Regression model } & \multicolumn{3}{|c|}{ F-value (2.17)=10.220 } \\
\hline Variable & $\begin{array}{c}\text { Standardised Beta } \\
\text { regression coproficient }\end{array}$ & $\boldsymbol{t}$-value & $p$-level \\
\hline HVTO & 1.21 & 5.79 & $* .00$ \\
\hline EATO & 0.14 & 0.73 & .48 \\
\hline SABPP & -0.32 & -1.98 & .07 \\
\hline HATO & -0.49 & -2.66 & $* .02$ \\
\hline EAHCG & 0.38 & 1.88 & .08 \\
\hline LA & 0.26 & 1.44 & .17 \\
\hline
\end{tabular}

Table 13. Forward Stepwise Multiple Regression Analysis - method of gradual extension of the model for a group of adolescents aged 16 to 18 years

Note: ${ }^{*} p \leq .05$. 
Table 14. Backward Stepwise Multiple Regression Analysis method of gradual reduction of the model for a group of adolescents aged 16 to 18 years

Note: ${ }^{*} p \leq .05$.

\begin{tabular}{|c|c|c|c|}
\hline Regression model & \multicolumn{3}{|c|}{$F$-value (6.13)=9.437 } \\
\hline Variable & $\begin{array}{c}\text { Standardised Beta } \\
\text { regression coproficient }\end{array}$ & $t$-value & $p$-level \\
\hline TOA & -1.21 & -4.15 & ${ }^{* .00}$ \\
\hline VVTO & 1.30 & 4.45 & ${ }^{*} .00$ \\
\hline
\end{tabular}

However, a statistically significant influence of parameters that define highly important arm swing in the preparatory phase, registered in the analysis of the jump performed by students of the Faculty of Kinesiology, is still missing (shoulder angle at the beginning of the preparatory phase, shoulder angle at the lowest point of the centre of gravity and shoulder angle at the highest point of the centre of gravity).

\section{DISCUSSION}

In accordance with the objective of this study, the results of Forward and Backward Multiple Regression Analysis for a group of students of the Faculty of Kinesiology showed that the length of a standing long jump was statistically significantly influenced by horizontal velocity at take-off, the take-off angle and the variables that define arm swing (shoulder angle at the beginning of the preparatory phase, shoulder angle at the lowest point of the centre of gravity, elbow angle at takeoff and shoulder angle at the highest point of the centre of gravity). Obtained results confirmed the conclusions of previous studies of Ashby and Delp (2006), Ashby and Heegaard (2002), Lees, Vanrenterghem, and Clercq (2000), and Wakai and Linthorne (2005) who found that the proficiency of the standing long jump depended on three components: horizontal velocity at take-off, takeoff angle and arm swing during a jump.

Contrary to the results obtained on the group of students of the Faculty of Kinesiology, results obtained on boys aged 4-6 years showed that the length of the jump depended only on the parameters of horizontal and vertical velocity at take-off.

For the respondents of this group, the length of the jump was not significantly affected by variables that define the geometry of the body during a jump. It can be suggested that in children of preschool age, expected stereotype of motion characterised by leg work coordinated with symmetrical arm swing, is still not sufficiently developed.
Similar results come from research of Wilson and Brown (1993). On the basis of the obtained differences in kinematic parameters of the take-off and landing phases in children aged 4-7 years, they concluded that with improvement of the geometry of the body, in the observed phases, the subjects achieved better results. Harrison and Keane (2007) found that the group of respondents between the ages of 5 to 6 years who practiced different types of jumps during period six weeks $(2 \times 30 \mathrm{~min})$ significantly improved their performance and stereotype of standing long jump motion, while in a group of subjects of the same age who exercised only vertical jump there were no statistically significant changes. Labiadh, Ramanantsoa and Golomer (2010) examined the coordination of body segments in 3- to 7-year-olds during the performance of the standing long jump, based on jump imitation performed by adults. From the results of the video analysis they found that the experimental groups achieved a large number of coordination modes of jump and large variations in duration of the jump, which means that at that age the technical performance of the standing long jump has not yet become stable. Lv (2012) found the exact quantitative changes of motor skills in children from 3 to 6 years of age during performance of the standing long jump, concluding that the geometry of the jump significantly changed with age.

Furthermore, in this study it has been found that the length of the jump for 4- to 6-year-old boys is significantly affected not only with horizontal but also with vertical velocity at take-off. On the basis of these results it can be argued that in children of that age the direction of the jump is not yet defined and sufficiently controlled. This is supported by previous studies by Davies and Jones (1993), Fukashiro et al. (2005), and Robertson and Fleming (1987), who concluded that there were several important factors influencing the direction of the jump and differentiating horizontal from vertical jump. These factors were the geometry of 
the body at take-off phase defined by the hip angle at take-off and trunk inclination (take-off angle). Roy, Youm and Roberts (1973) have also analysed the components of vertical and horizontal jump in subjects aged 7-16 years. They concluded that the parameters defining the direction of the jump were partly constant after 10 years, and finally constant after 13 years of life.

Kinematic parameters that are relevant for the performance of the standing long jump in boys aged 7-9 years indicate that children after proceeding from kindergarten to school pass through certain changes in performance technique of standing long jump. Although, one of the parameters defining the CG trajectory of the jump (vertical velocity at takeoff) has not yet become stable, certain parameters that define the geometry of the body before and at take-off phase appeared as it was the case with the students who represented the model of the jump. In particular, it is evident that for 7- to 9year-olds: besides horizontal velocity at take-off, the parameters hip angle at the lowest point of the centre of gravity and the shoulder angle at takeoff and take-off angle play an important role in forming the trajectory of the jump.

Similar results were obtained in research of Phillips, Clark and Petersen (1985). The authors found that the angle of shoulders significantly increased with age. Also, statistically significant differences were obtained in variable inclination of the body and horizontal displacement of the centre of gravity. Based on the obtained results they concluded that from 3 to 9 years of age the final length of the jump was significantly affected by the moving the centre of gravity forward from the take-off line, which decreases take-off angle. Also, Zheng, Chiu, Hsieh and Liao (2007) found a statistically significant positive correlation between the parameters of jump length and take-off angle, landing angle as well as with the inclination of the trunk in landing in students from the 1st to the 3 rd grade, while on the basis of a comparison of the standing long jump of 6- to 11-year-olds and young athletes Zhouye, Yoshimasa, Yun and Kazuhiko (2010) concluded that a coordinated arm swing was very important during the standing long jump performance and that in children of primary school age the proper functioning of the arms, hip and knee joints in the preparatory phase before take-off was still not developed.
In this study, the results of the analysis of boys aged 10 to 12 years suggests that the length of the jump still significantly depends on the parameter vertical velocity at take-off, whicht shows that parameters which define the trajectory of the jump are still not constant. Opposite to the groups of 4- to 6- and 7- to 9-year-olds, parameters that in more detail define the geometry of the body prior, at take-off and in flight phase of standing long jump, appear (knee angle at the lowest point of the centre of gravity, hip angle at take-off, take-off angle and shoulder angle at the highest point of the centre of gravity). However, statistically significant influence of variables that define arm swing in the preparatory phase of the jump was not registered, as it was the case with students of the Faculty of Kinesiology. Roy et al. (1973) have also found that for boys from 7 to 13 years, while performing standing long jump, not only horizontal shift, but also vertical shift of the centre of gravity during the take-off plays a significant role during the take-off.

Furthermore, differing to previous groups of subjects, in boys aged 10 to 12 years, a parameter landing angle has statistically significant influence on the length of the standing long jump. Following this, it can be concluded that in that age group geometry of the body, during the flight and at the moment of landing, is becoming more similar to the model obtained from the students of the Faculty of Kinesiology. According to the collected data, it is evident that respondents who achieve lower landing angle by stretching arms and lower legs forward, together with forward bent, have accomplished better final results of the standing long jump, as it was confirmed by Decker, Torry, Wyland, Strett and Steadman (2003) and Wakai and Linthorne (2005).

Contrary to the results of groups of subjects from 4 to 6,7 to 9 and 10 to 12 years, in 13- to 15 -year-olds a statistically significant influence of parameter vertical velocity at take-off on the length of the jump was not registered, and the length of the jump is primarily predetermined by hip angle and horizontal velocity at take-off. Roy et al. (1973) also found that in boys after the age of 13 a significant role during performing standing long jump was played by the horizontal displacement of the centre of gravity.

Compared to previously analysed groups biomechanical characteristics of standing long jump performed by respondents aged 13 to 15 , were most 
similar to those obtained on the students of Faculty of Kinesiology. This leads to the conclusion that in that age a stabilization of kinematic parameters that determine the trajectory of the jump occurs.

Based on the results obtained for the group of adolescents (age 16 to 18) it can be noted that, although previous research confirmed the presence of maturation and stabilization of movement structures of standing long jump (Roy et al., 1973, Wang, Lin, Huang \& Yang 2002; Zhouye et al., 2010), this study showed that adolescents still had certain technical problems with the standing long jump performance. Namely, there was still no statistically significant influence of parameters that define the important arm swing in the preparatory phase as well as the blocking action of arms in flight phase of the jump. This has also been confirmed by group of authors who concluded that standing long jump was a complex motor skill playing a fundamental role on the final result of the standing long jump and the coordination of its segments (Ashby \& Delp, 2007; Chow, Koh, Davids, Button \& Rein, 2014; Lee \& Cheng, 2008; Nagano et al., 2007; Wakai \& Linthorne, 2005; Weimar, Martin \& Wall, 2011).

Therefore, the obtained results in this study support the hypothesis that there would be a significant influence of certain kinematic parameters on the proficiency of standing long jump test performance in boys and adolescents aged $4-18$ years at the $95.0 \%$ confidence level.

\section{CONCLUSION}

Standing long jump test is a complex movement in which the jumper, in order to achieve the longest length of the jump, must execute a combination of very demanding coordinated actions. The aim of this study was to determine kinematic parameters relevant to the proficient performance of standing long jump test in boys and adolescents aged 4 to 18 years.

On the basis of the obtained results it can be concluded that the performance of standing long jump test is determined by specific kinematic parameters different for each of the age groups analysed in this study, including students from the Faculty of Kinesiology whose execution of the standing long jump was treated as a model. This confirmed the hypothesis that there would be a significant influence of certain kinematic parameters on the proficiency of standing long jump test performance in boys and adolescents aged $4-18$ years.

Results of this study showed that the length of the standing long jump performed by students depended on horizontal velocity at take-off, take-off angle and the parameters that determine the arm swing during the jump (shoulder angle at the beginning of the preparatory phase, shoulder angle at the lowest point of the centre of gravity, elbow angle at take-off and shoulder angle at the highest point of the centre of gravity), while in other analysed different age groups it was observed that these parameters were changing significantly with age.

In pre-school children (4-6 year olds) standing long jump is determined only by the horizontal velocity at take-off. In their performance of this task almost all of the components that lead to the successful performance of the jump are missing (arm swing, take-off angle, as well as the parameters that determine the trajectory of the jump). Furthermore, in early school age (7-12 year olds), the important element that affects the length of the standing long jump also is parameter take-off angle, while at the age of 13-18 years, parameter hip angle at take-off is also statistically significant.

It is interesting that in all of the analysed age groups the parameters that determine the arm swing during the jump were not statistically significant.

Since the standing long jump is a standard test for the assessment of lower limb explosive strength, according to the results obtained by this research, which proved that in different age groups different techniques of performance of this task exist, it is reasonable to ask a question whether the test standing long jump has the same object of measurement in respondents of different age, especially for younger subjects.

\section{REFERENCES}

Ashby, B. M., \& Delp, S. L. (2006). Optimal control simulations reveal mechanisms by which arm movement improves standing long jump performance. Journal of Biomechanics, 39, 1726-1734. doi:10.1016/j. jbiomech.2005.04.017
Ashby, B. M., \& Heegaard, J. H. (2002). Role of arm motion in the standing long jump. Journal of Biomechanics, 35, 1631-1637. doi: 10.1016/S00219290(02)00239-7 
Blackburn, J. R., \& Morrissey, M. C. (1998). Relationship between open and closed kinetic chain strength of the lover limb and jumping performance. Journal of Orthopaedic and Sports Physical Therapy, 27(6), 430-435.

Chow, J. Y., Koh, M., Davids, K., Button, C., \& Rein, R. (2014). Effects of different instructional constraints on task performance and emergence of coordination in children. European Journal of Sport Science, 14(3), 224-232. doi: 10.080/17461391.2013.780097

Davies, B. N., \& Jones, K. G. (1993). An analysis of the performance of male students in the vertical and standing long jump test and the contribution of arm swing. Journal of Human Movement Studies, 24, 25-38.

Decker, M. J., Torry, M. R., Wyland, D. J., Strett, W. I., \& Steadman, J. R. (2003). Gender differences in lover extremity kinematics, kinetics and energy absorption during landing. Clinical Biomechanics, 18, 662-669. doi:10.1016/S0268-0033(03)00090-1

Domire, Z. J., \& Challis, J. H. (2010). An induced energy analysis to determine the mechanism for performance enhancement as a result of arm swing during jumping. Sports Biomechanics, 9(1), 38-46. doi: 10.1080/14763141003692639

Fukashiro, S., Besier, T. F., Barrett, R., Cochrane, J., Nagano, A., \& Lloyd, D. G. (2005). Direction control in standing horizontal and vertical jumps. International Journal of Sport and Health Science, 3, 272-279. doi: 10.5432/ijshs.3.272

Harrison, A. J., \& Keane, N. (2007). Effects of Variable and Fixed Practice on the Development of Jumping Ability in Young Children. In H. J. Menzel and M. H. Chagas (Eds.), International Symposium of Biomechanics in Sports, 25(1), 164-167.

Horita, T., Kitamura, K., \& Kohno, N. (1991). Body configuration and joint moment analysis during standing long jump in 6-yr-old children and adult males. Medicine and Science in Sports and Exercise, 23(9), 1068-1077. doi: 10.1249/00005768-199109000-00012

Labiadh, L., Ramanantsoa, M., \& Golomer, E. (2010). Preschool-aged children'sjumps, Imitationperformances. Journal of Electromyography and Kinesiology, 20, 322 329. doi: 10.1016/j.jelekin.2009.05.005

Lee, J., \& Cheng, K. (2008). Efect of shoulder strenght on the flight distance in the standing long jump. In J. H. Kwon, J. Shim, J. K. Shim and I. Shin (Eds.), International Symposium of Biomechanics in Sports (pp. 402-405). Konstanz: Sport Science University of Konstanz.

Lees, A., Vanrenterghem, J., \& Clercq, D. D. (2004). Understanding how an arm swing enhances performance in the vertical jump. Journal of Biomechanics, 37, 19291940. doi: 10.1016/j.jbiomech.2004.02.021

Lorger, M., Hraski, M., \& Hraski, Ž. (2012). The Effects of Motor Learning on Results of Standing Long Jump
Performed by Female Students. Sport Science, 5(1), 27-31.

Lv, R. (2012). Kinematic analysis of standing long jump for 3 to 6 years old children. Lecture Notes in Electrical Engineering, 136, 363-367. doi: 10.1007/978-3-64226001-8_47

Mackala, K., Stodolka, J., Siemienski, A., \& Čoh, M. (2012). Biomechanical analysis of standing long jump from varying starting positions. Journal of Strength \& Conditioning Research, 27(10), 2674-2684. doi: 10.1519/JSC.0b013e31825fce65

Malina, R. M. (2004). Motor development during infancy and early childhood: Overview and suggested directions for research. International Journal of Sport and Health Science, 2, 50-66. doi: 10.5432/ijshs.2.50

Nagano, A., Komura, T., \& Fukashiro, S. (2007). Optimal coordination of maximal-effort horizontal and vertical jump motions - a computer stimulation study. BioMedical Engineering OnLine, 6(1), 20. doi: 10.1186/1475-925X-6-20

Newton, R. U., \& Kraemer, W. J. (1994). Developing explosive muscular power: Implications for a mixed methods training strategy. Strength and Conditioning Journal, 16(5), 20-31. doi: 10.1519/1073-6840(1994)

Phillips, S., Clark, J. E., \& Petersen, R. D. (1985). Developmental differences in standing long jump take off parameters. Journal of Human Movement Studies, 11, 75-87.

Pišot, R., \& Planinšec, J. (2010). Motor structure and basic movement competences in early child development. Annales Kinesiologiae, 1(2), 145-165.

Popeska, B., Georgiev, G., \& Mitevski, O. (2009). Structure of motor space in children at 7 year age. Physical Education and Sport, 48(8), 19-24.

Robertson, D. G., \& Fleming, D. (1987). Kinetics of standing broad and vertical jumping. Canadian Journal of Applied Sport Sciences, 12(1), 19-23.

Roy, B., Youm, Y., \& Roberts, E. (1973). Kinematics and Kinetics of the Standing Long-Jump in 7-, 10-, 13and 16-Year-Old Boys. Medicine and Sport, 3, 409-416.

Seyfarth, A., Friedrich, A., Wank, V., \& Blickhan, R. (1999). Dynamics of the long jump. Journal of Biomechanics, 32, 1259-1267. doi: 10.1016/S00219290(99)00137-2

Szerdiova, L., Simsik, D., \& Dolna, Z. (2012). Assessment of kinematics of sportsmen performing standing long jump in 2 different dynamical conditions. Metrology and Measurement Systems, 19(1), 85-94. doi: 10.2478/v10178-012-0007-x

Vitasalo, J. T. (1988). Evaluation of explosive strength for young and adult athletes. Research Quarterly for Exercise and Sport, 59, 9-13.

Wakai, M., \& Linthorne, N. P. (2005). Optimum takeoff angle in the standing long jump. Human Movement Science, 24, 81-96. doi: 10.1016/j.humov.2004.12.001 
Wang, L. I., Lin, D. L., Huang, C., \& Yang, C. (2002). Biomechanical analysis during countermovement jump in children and adults. In K. E. Gianikellis (Ed.), 20 International Symposium of Biomechanics in Sports (pp. 374-377). Konstanz: Sport Science University of Konstanz.

Weimar, W. H., Martin, E. H., \& Wall, S. J. (2011). Kindergarten students' qualitative responses to different instructional strategies during the horizontal jump. Physical Education and Sport Pedagogy, 16(3), 213222. doi: 10.1080/17408989.2010.541235

Wilson, D. J., \& Brown, E. W. (1993). A biomechanical comparison of developmental stages of the standing long jump. In J. Hamill, T. R. Derrick and E. H. Elliott (Eds.), 11 International Symposium on Biomechanics in Sport (pp. 69-71). Konstanz, Sport Science University of Konstanz.
Wu, W., Wu, J., Lin, H., \& Wang, G. (2003). Biomechanical analysis of the standing long jump. Biomedical Engineering, Applications, Basis and Communications, 15(5), 186-192. doi: 10.4015/ S1016237203000286

Zheng, Z., Chiu, W., Hsieh, M., \& Liao, Y. (2007). The study of the corresponding influence factors of standing long jump action performed among the first-grade to the third students in the Elementary School. Journal of Biomechanics, 40(2), S627. doi: 10.1016/S00219290(07)70615-2

Zhouye, C., Yoshimasa, I., Yun, W., \& Kazuhiko, W. (2010). Developmental movement of standing long jump in elementary school children by kinematics analysis. Journal of Strength and Conditioning Research, 24, 1. doi: 10.1097/01.JSC.0000367255.46870.ff 